\title{
Inhibitory effects of genistein in combination with gefitinib on the hepatocellular carcinoma Hep3B cell line
}

\author{
YONGXI TONG $^{1 *}$, MINGSHAN WANG $^{1 *}$, HAIJUN HUANG $^{1}$, JIAJIE ZHANG $^{1}$, \\ YICHENG HUANG $^{1}$, YINGJUN $\mathrm{CHEN}^{2}$ and HONGYING PAN ${ }^{1}$ \\ ${ }^{1}$ Department of Infectious Diseases, Zhejiang Provincial People's Hospital, Hangzhou, Zhejiang 310014; \\ ${ }^{2}$ Department of Infectious Diseases, Tiantai People's Hospital of Zhejiang Province, Taizhou, Zhejiang 317200, P.R. China
}

Received June 1, 2018; Accepted July 8, 2019

DOI: $10.3892 /$ etm.2019.8027

\begin{abstract}
Combination therapy is an important method for treating advanced hepatocellular carcinoma (HCC). Gefitinib is an epidermal growth factor receptor (EGFR) inhibitor, which has profound effects on HCC. The purpose of the present study was to investigate the effects of genistein in combination with gefitinib on the proliferation and apoptosis of HCC cells and the associated mechanism. Cell counting kit- 8 assay was performed to calculate the $\mathrm{IC}_{50}$ values and cytotoxicity, whilst flow cytometry was used to assess cell apoptosis. Protein expression was detected using western blot analysis. The $\mathrm{IC}_{50}$ of genistein and gefitinib on Hep3B cells were calculated to be 128.078 and $13.657 \mu \mathrm{M}$, respectively. Genistein in combination with gefitinib significantly inhibited cell viability, promoted apoptosis and reduced EGFR, vascular endothelial growth factor receptor and platelet-derived growth factor receptor phosphorylation. Genistein in combination with gefitinib promoted the expression of cleaved caspase- 3 and cleaved poly ADP-ribose polymerase. In addition, combined treatment of genistein and gefitinib strongly inhibited the activation of the Akt/Erk/mTOR signaling pathway. In conclusion, findings from the present study suggest that genistein in combination with gefitinib inhibit HCC cell proliferation and promote apoptosis by inhibiting the Akt/Erk/mTOR pathway.
\end{abstract}

\section{Introduction}

Hepatocellular carcinoma (HCC) is one of the most common malignancies (1). HCC has the fifth highest incidence and the

Correspondence to: Dr Hongying Pan, Department of Infectious Diseases, Zhejiang Provincial People's Hospital, 158 Shangtang Road, Hangzhou, Zhejiang 310014, P.R. China

E-mail: hongyingp_panhy@163.com

*Contributed equally

Key words: hepatocellular carcinoma, gefitinib, genistein, caspase-3, mammalian target of rapamycin third highest mortality of all malignancies worldwide $(1,2)$, leading to $>600,000$ deaths annually (3). However, effective treatment for HCC remains elusive (4).

Liver resection and transplantation are currently the primary methods for treating HCC (5). However, due to unobservable symptoms in the early stages of HCC pathogenesis, most patients are diagnosed with HCC in the advanced stages (4). Surgical intervention for advanced HCC is not effective and chemotherapy is the only therapeutic option (6). However, traditional chemotherapeutic agents, including cisplatin, doxorubicin and fluorouracil, produce unsatisfactory outcomes, adverse side effects and drug resistance (6). With the emergence of targeted drugs such as small molecule kinase inhibitors, considerable progress has been made in the treatment of HCC (7). For patients with HCC, where surgery is not recommended, palliative treatment using sorafenib is currently the only clinical solution (8). However, since some patients with HCC also exhibit insensitivity or resistance to sorafenib, other chemotherapeutic options are required (8).

Gefitinib is a small molecule inhibitor of epidermal growth factor receptor (EGFR) (9). As a transmembrane protein, EGFR can induce cell proliferation by phosphorylating mitogen-activated protein kinase (MAPK), Akt and JNK (10-12). Previous studies have confirmed that increased expression of EGFR is an important feature to the occurrence and development of HCC. In particular, Schiffer et al (13) has found that gefitinib inhibited hepatoma cell proliferation, however, any further mechanism remains unclear.

Genistein, also known as 5,7,4'-trihydroxyisoflavone, is an isoflavone originally found in Glycine $\max (14)$, which has demonstrated the potential to reduce the risk of developing liver, lung and breast cancer (15). In hepatoma cells, a previous study has found that genistein treatment inhibited proliferation whilst promoting apoptosis (16) and inhibited EGFR activation (17). However, to the best of our knowledge, no study on the combined effects of gefitinib and genistein on liver cancer has been conducted.

Therefore, the purpose of the present study was to investigate the effect of gefitinib and genistein on the physiology of hepatocellular carcinoma cells and to investigate the mechanism by testing the Akt/Erk/mTOR pathway. 


\section{Materials and methods}

Cell culture. The HCC cell line Hep3B was purchased from American Type Culture Collection (cat. no. ATCC ${ }^{\circledR}$ HB-8064). The cells were cultured in RPMI 1640 medium supplemented with $10 \%$ fetal bovine serum (FBS) and $100 \mathrm{U} / \mathrm{ml}$ of penicillin-streptomycin maintained in a humidified atmosphere at $37^{\circ} \mathrm{C}$ under $5 \% \mathrm{CO}_{2}$. RPMI 1640, FBS and penicillin-streptomycin were purchased from Gibco (Thermo Fisher Scientific, Inc.). Hep3B cells $\left(5 \times 10^{3}\right.$ cells/well) were cultured with different concentrations of genistein $(10,20$, 40, 80 and $160 \mu \mathrm{M}$; cat. no. G0272; Tokyo Chemical Industry Development Co., Ltd.) or gefitinib $(1,2.5,5,10$ and $20 \mu \mathrm{M}$; cat. no. S1025, Selleck Chemicals) for $48 \mathrm{~h}$ at $37^{\circ} \mathrm{C}$, in order to calculate the $\mathrm{IC}_{50}$ values. Hep3B cells were cultured in the presence of PBS (control group), $120 \mu \mathrm{M}$ genistein (genistein group), $12 \mu \mathrm{M}$ gefitinib (gefitinib group) and $127.6 \mu \mathrm{M}$ genistein $+9.8 \mu \mathrm{M}$ gefitinib (combination group) at $37^{\circ} \mathrm{C}$, with the inhibition of cell growth analyzed at $0,12,24,36,48,60$ and $72 \mathrm{~h}$ for each group.

Cell cytotoxicity assay. Cell viability $\left(5 \times 10^{3}\right.$ cells/well $)$ treated with genistein $(10,20,40,80$ and $160 \mu \mathrm{M})$ or gefitinib $(1,2.5,5,10$ and $20 \mu \mathrm{M})$ for $48 \mathrm{~h}$ at $37^{\circ} \mathrm{C}$ was detected by using cell counting kit-8 (CCK-8) assay (Beyotime Institute of Biotechnology). Diluted CCK-8 reagent was added and cultured at $37^{\circ} \mathrm{C}$ in a humidified atmosphere under $5 \% \mathrm{CO}_{2}$ for $4 \mathrm{~h}$. Optical density in each well at $450 \mathrm{~nm}$ was subsequently measured using a microplate reader $\left(\mathrm{ELx} 800^{\mathrm{TM}}\right.$; Omega Bio-Tek, Inc.). The cellular proliferation inhibition rates were calculated as: $\left(1-\mathrm{OD} / \mathrm{OD}_{0 \mu \mathrm{M}}\right) \times 100 \%$.

Flow cytometry assay. After the treatment of $120 \mu \mathrm{M}$ genistein (genistein group), $12 \mu \mathrm{M}$ gefitinib (gefitinib group) or $127.6 \mu \mathrm{M}$ genistein $+9.8 \mu \mathrm{M}$ gefitinib (combination group) and culturing for $72 \mathrm{~h}\left(5 \times 10^{3}\right.$ cells/well), cell apoptosis was measured using BD Pharmingen ${ }^{\mathrm{TM}}$ PE Annexin V-FITC/PI Apoptosis Detection Kit I (BD Biosciences) according to manufacturer's protocol. The samples were incubated at room temperature in the dark for $10 \mathrm{~min}$. BD FACSCalibur ${ }^{\mathrm{TM}}$ Flow Cytometer and BD FACStation ${ }^{\mathrm{TM}}$ Software v6.1 x (BD Biosciences) was used to analyze cell apoptosis.

Western blot analysis. Cells were lysed using NP40 lysis buffer (Beyotime Institute of Biotechnology). The supernatant was collected by centrifuging the cell lysate at $10,000 \mathrm{xg}$ at $4^{\circ} \mathrm{C}$ for $15 \mathrm{~min}$. Bicinchoninic acid assay was used to determine the protein concentration. The proteins ( $20 \mu \mathrm{g} / \mathrm{lane})$ were separated using $10 \%$ SDS-PAGE followed by transfer onto PVDF membranes. The membranes were blocked with $5 \%$ fat-free milk, diluted in PBS, at room temperature for $2 \mathrm{~h}$ prior to incubation with primary antibodies against anti-pro-caspase-3, (1:800, cat. no. ab13847), anti-cleaved-caspase-3 (1:600; cat. no. ab49822), anti-cleaved-poly ADP ribose polymerase (cleaved-PARP; 1:700; cat. no. ab32064), anti-EGFR (1:2,000; cat. no. ab32562), anti-platelet-derived growth factor $\alpha$ (PDGF; 1:500; cat. no. ab38562), anti-pan-Akt (Akt; 1:800; cat. no. ab8805), anti-phospho-pan-Akt (phospho T308; p-Akt; 1:800, cat. no. ab38449), anti-Erk1/2 (1:800, cat. no. ab54230), anti-p-Erk1/2 (1:600; cat. no. ab201015), anti-mTOR (1:800; cat. no. ab2732) or anti-p-mTOR (1:600; cat. no. ab109268) at $4^{\circ} \mathrm{C}$ overnight. All primary antibodies were purchased from Abcam. The membranes were subsequently incubated with goat anti-mouse $\operatorname{IgG}(1: 8,000$; cat. no. ab6785; Abcam), rabbit anti-mouse $\operatorname{IgG},(1: 9,000$; cat. no. ab99697; Abcam), mouse anti-rabbit $\operatorname{IgG}(1: 7,000$; cat. no. BA1034; Invitrogen; Thermo Fisher Scientific, Inc.) and donkey anti-rabbit IgG (1:5,000; cat. no. NL004; R\&D Systems, Inc.) secondary antibodies at room temperature for $1.5 \mathrm{~h}$. Protein bands were visualized using BeyoECLMoon ECL reagent (Beyotime Institute of Biotechnology) and Quantity One v4.6.2 (Bio-Rad Laboratories, Inc.) quantitative analysis software.

Reverse transcription-quantitative PCR (RT- $q P C R)$. Total RNA was extracted using TRIzol (Thermo Fisher Scientific, Inc.) according to the manufacturer's protocol and quantified using a NanoDrop spectrometer (Thermo Fisher Scientific, Inc.). RNA was reverse transcribed into cDNA at $42^{\circ} \mathrm{C}$ for $30 \mathrm{~min}$ and $85^{\circ} \mathrm{C}$ for $5 \mathrm{~min}$, using the iScript ${ }^{\mathrm{TM}}$ cDNA Synthesis kit (Bio-Rad Laboratories, Inc.) according to the manufacturer's protocol. qPCR was then performed using FastStart Universal SYBR ${ }^{\circledR}$ Green Master kit (Roche Diagnostics) in the ABI StepOne system (Applied Biosystems; Thermo Fisher Scientific, Inc.) according to manufacturers' protocols. Each reaction system was prepared as follows: cDNA template, $2.5 \mu \mathrm{l}$; forward primers $(10 \mu \mathrm{M}), 1 \mu \mathrm{l}$; reverse primers $(10 \mu \mathrm{M}), 1 \mu \mathrm{l}$; 2X SYBR ${ }^{\circledR}$ Green master mix, $10 \mu \mathrm{l}$ and $\mathrm{ddH}_{2} \mathrm{O}, 5.5 \mu$ l. The following thermocycling conditions were used for the qPCR: Initial denaturation for $2 \mathrm{~min}$ at $95^{\circ} \mathrm{C}$; 40 cycles of $15 \mathrm{sec}$ at $95^{\circ} \mathrm{C}, 25 \mathrm{sec}$ at $60^{\circ} \mathrm{C}$ and $60 \mathrm{sec}$ at $72^{\circ} \mathrm{C}$. Expression levels were quantified using the $2^{-\Delta \Delta \mathrm{Ca}}$ method with GAPDH as the internal reference (18). The list of primers used for this study is included in Table I.

Statistical analysis. Data are presented as the mean \pm standard deviation. Statistical analysis was performed using SPSS 20 software (IBM Corp.). One-way ANOVA followed by Tukey's multiple comparisons post hoc test was performed to analyze differences between experimental groups. $\mathrm{P}<0.05$ was considered to indicate a statistically significant difference.

\section{Results}

$I C_{50}$ determination of genistein and gefitinib. By measuring Hep3B cell cytotoxicity under different concentrations of genistein and gefitinib after $48 \mathrm{~h}$, the $\mathrm{IC}_{50}$ values of genistein and gefitinib were calculated to be 127.603 and $9.818 \mu \mathrm{M}$, respectively (Fig. 1A and B). These concentrations were therefore used for subsequent experiments.

Apoptosis of Hep3B cells induced by genistein and gefitinib. Comparing the cytotoxicity (killing the cells) of the control, genistein, gefitinib and combination groups over a 72-h time course, it was found that the cytotoxicity in the combination group was the highest (Fig. 2A). Flow cytometry was applied to detect the apoptosis of the control, genistein, gefitinib, and combination groups, after cells were cultured for $72 \mathrm{~h}$. The apoptosis in the genistein alone and gefitinib alone groups were significantly higher compared with that in the control group, whereas that of the combination group was the highest 
Table I. Sequences of primers used for reverse transcription-quantitative PCR.

Primer sequence $\left(5^{\prime}-3^{\prime}\right)$

Primer name

Forward

Reverse

EGFR

AACACCCTGGTCTGGAAGTACG

GAGGAAGCCGAGATGCCCC

PDGF AGTATGACTCCACTCACGGC

TCGTTGGACAGCCTTCAAGACC
TGCTGTGGATCTGACTTCGAG
CACCAGTAGACTCCACGACA

GAPDH

EGFR, epidermal growth factor receptor; PDGF, platelet-derived growth factor.
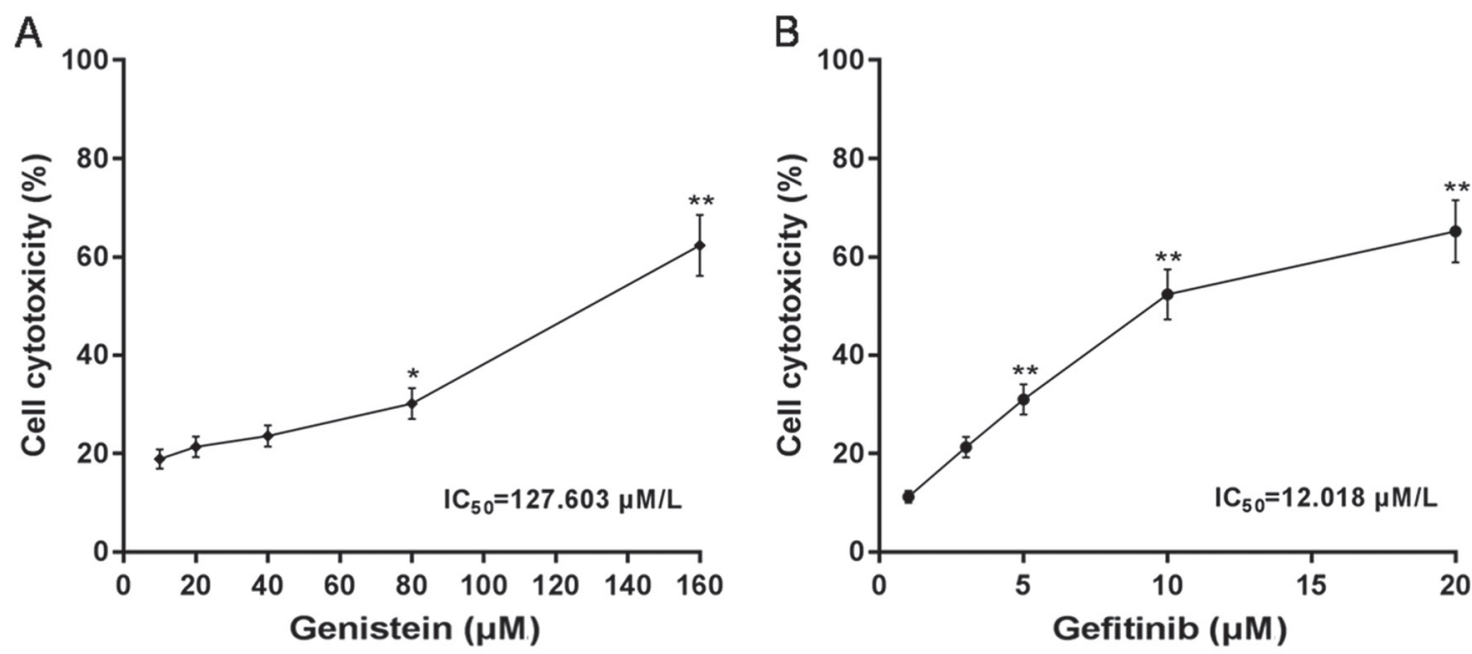

Figure 1. Inhibitory effect of different concentrations of genistein and gefitinib on Hep3B cells after 48 h. (A) CCK-8 assay was used to measure the cytotoxicity rates of $\mathrm{Hep} 3 \mathrm{~B}$ cells under different concentrations of genistein. The $\mathrm{IC}_{50}$ of genistein was calculated to be $127.603 \mu \mathrm{mol} / 1$. (B) CCK- 8 assay was used to measure the cytotoxicity of $\mathrm{HEP} 3 \mathrm{~B}$ cells at different concentrations of gefitinib. The $\mathrm{IC}_{50}$ of gefitinib was calculated to be $9.818 \mu \mathrm{mol} / 1$. CCK-8, cell counting kit- $8 .{ }^{*} \mathrm{P}<0.05$ and ${ }^{* * *} \mathrm{P}<0.01$ vs. cell cytotoxicity at $0 \mathrm{~h}$.

compared with the other three groups (Fig. 2B). This suggests that genistein in combination with gefitinib enhanced hep3b cell apoptosis.

Effects of genistein and gefitinib on the activity of EGFR, PDGF, and the expression of proteins associated with apoptosis. Expression levels of pro-caspase-3, cleaved-caspase-3, cleaved-PARP, EGFR and PDGF were detected using western blot analysis. The expression levels of pro-caspase-3 protein was significantly reduced in the genistein alone and gefitinib alone groups, whilst the protein expression levels of cleaved-caspase-3 and cleaved-PARP were significantly increased compared with the control group (Fig. 3A-D). When genistein and gefitinib were combined together, these observed effects on the expression of proteins associated with apoptosis were significantly enhanced compared with when either drug was used alone (Fig. 3A-D).

RT-qPCR and western blotting results revealed that either genistein or gefitinib treatment alone significantly downregulated the expression of EGFR and PDGF mRNA and protein, which was significantly enhanced by the combined addition of genistein and gefitinib (Fig. 3E-I). This suggest that that the enhanced effects of genistein in combination with gefitinib were achieved by inhibiting EGFR and PDGF expression and promoting the expression of pro-apoptotic proteins.

Effects of genistein and gefitinib on the Akt/Erk/mTOR pathway. Treatment with genistein alone, gefitinib alone or both in combination did not have statistically significant effects on the expression of total Akt, Erk and mTOR proteins (Fig. 4A-D). However, Akt, Erk and mTOR phosphorylation levels were significantly lower in genistein or gefitimib alone group, compared with control group. In addition, Akt, Erk and mTOR phosphorylation levels were significantly lower in the combination group compared with control, genistein or gefitinib alone, while Akt, Erk and Mtor phosphorylation levels were significantly lower in genistein or gefitinib groups compared with control group (Fig. 4A-D). These results suggest that genistein in combination with gefitinib can significantly reduce the Akt/Erk/mTOR pathway activity.

\section{Discussion}

Gefitinib is a small-molecule antitumor drug that can selectively inhibit EGFR and inhibit tumor cell proliferation to promote apoptosis (19). Indeed, gefitinib has demonstrated a high efficacy in treating lung and gastric cancer $(20,21)$. 
A

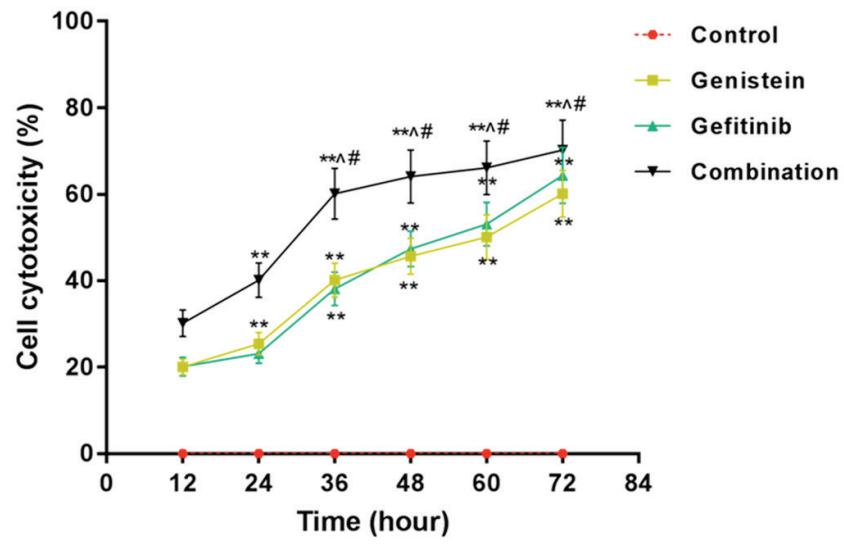

B
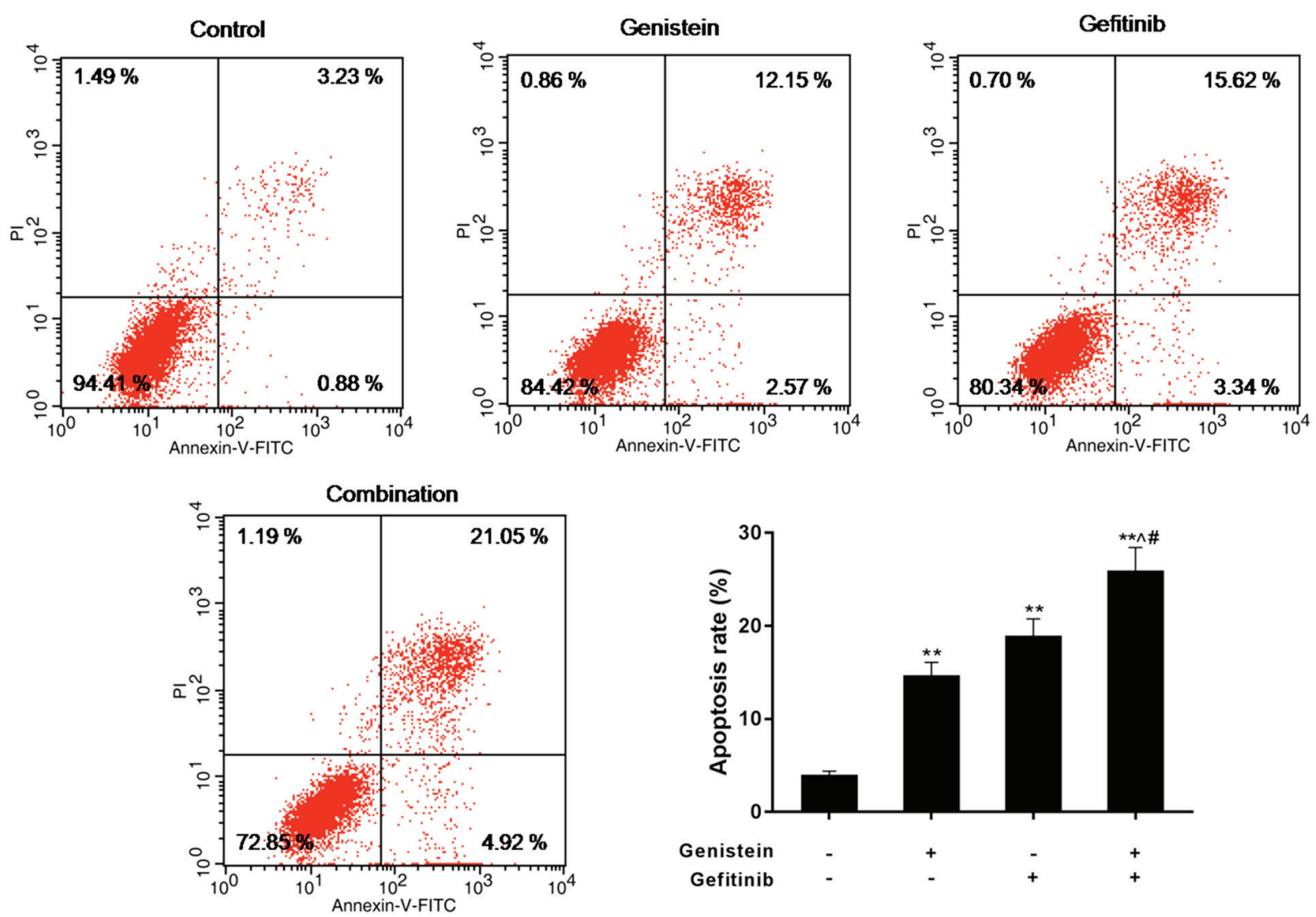

Figure 2. Effects of genistein and gefitinib on the proliferation and apoptosis of HEP3B cells. (A) Rates of cytotoxicity in response to $\mathrm{IC}_{50}$ concentrations of genistein alone, gefitinib alone and the two combined were determined using cell counting kit- 8 assay. (B) Apoptosis in response to $\mathrm{IC}_{50}$ concentrations of genistein alone, gefitinib alone and the two combined was determined using flow cytometry. ${ }^{* *} \mathrm{P}<0.01$ vs. control; ${ }^{\#} \mathrm{P}<0.05$ vs. genistein group; ${ }^{\wedge} \mathrm{P}<0.05$ vs. gefitinib group. FITC, fluorescein isothiocyanate; PI, propidium iodide. $\mathrm{IC}_{50}$, half maximal inhibitory concentration.

A recent study has shown that gefitinib exhibited inhibitory effects on HCC (22). By contrast, genistein is an isoflavone compound and an inhibitor of tyrosine protein kinase (TPK) (14). Studies have shown that inhibiting TPK activity using genistein prevented EGFR-mediated receptor autophosphorylation and mitotic signal transduction $(23,24)$. Genistein has been studied in various malignancies, including breast, lung and prostate cancer (25-27). However, only a limited number of studies have been conducted on the treatment of genistein on HCC.
The occurrence and development of HCC is closely associated with the abnormal expression of a number of proteins. In particular, one study has confirmed that the overexpression of EGFR was associated with the occurrence and development of liver cancer (28), where higher levels of EGFR expression were associated with poorer prognosis and higher recurrence rates in poorly differentiated HCC (29). Combination therapy is the most important method for treating advanced HCC (30), and to the best of our knowledge, there is currently no study investigating the effects of genistein in combination with gefitinib 
A

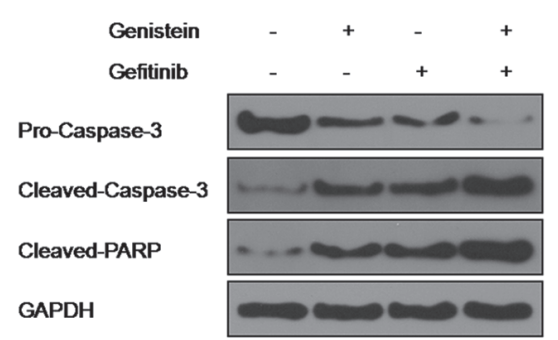

D

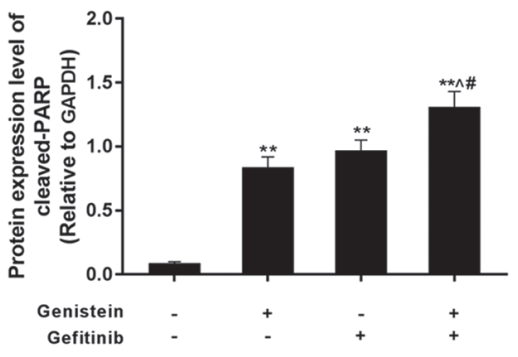

G

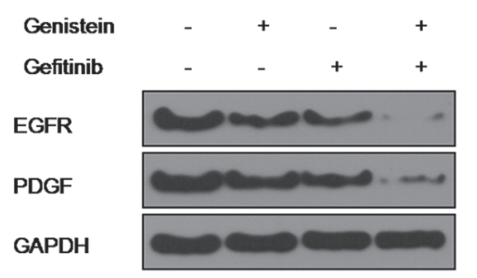

B

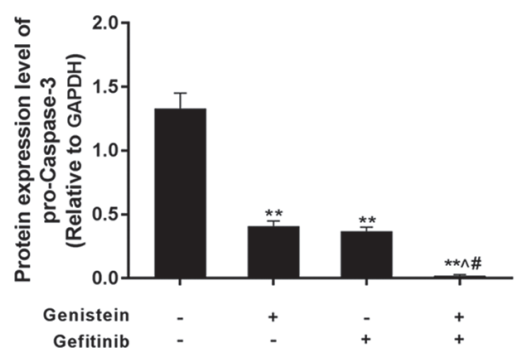

$\mathrm{E}$

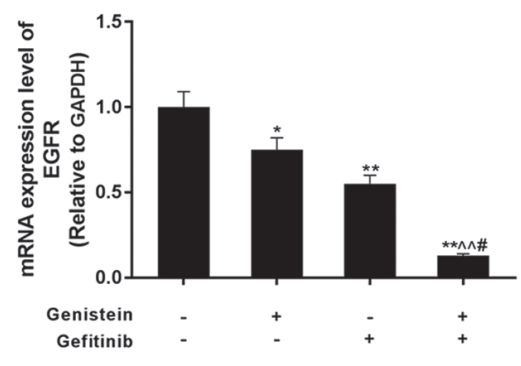

$\mathrm{H}$

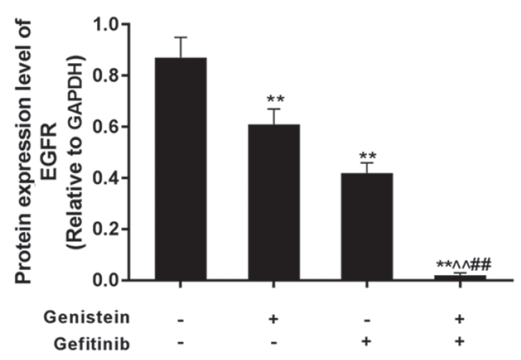

C

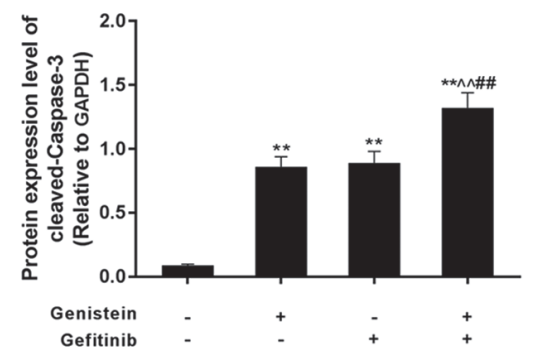

$\mathrm{F}$
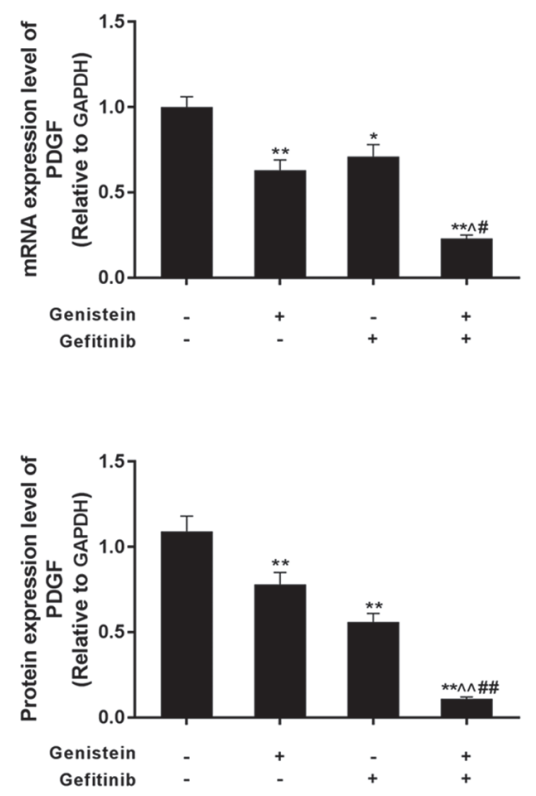

Figure 3. Effects of Genistein and Gefitinib on proteins associated with apoptosis, EGFR and PDGF. (A) Western blot analysis was performed to assess protein expression levels of (B) pro-caspase-3, (C) cleaved-caspase-3 and (D) cleaved-PARP proteins in the genistein alone, gefitinib alone and combination groups. Reverse transcription-quantitative PCR was used to measure mRNA expression levels of (E) EGFR and (F) PDGF in genistein alone, gefitinib alone and combination groups. (G) Western blotting was used to measure protein expression levels of (H) EGFR and (I) PDGF in genistein alone, gefitinib alone and combination groups. ${ }^{*} \mathrm{P}<0.05$ and ${ }^{* *} \mathrm{P}<0.01$ vs. control; ${ }^{\sharp} \mathrm{P}<0.05$ and ${ }^{\# \#} \mathrm{P}<0.01$ vs. genistein group; ${ }^{\wedge} \mathrm{P}<0.05$ and ${ }^{\wedge \wedge} \mathrm{P}<0.01$ vs. gefitinib group. EGFR, epidermal growth factor receptor; PDGF, platelet-derived growth factor; PARP, poly (ADP ribose) polymerase.

on HCC. Therefore, in the present study the effect of genistein combined with gefitinib on the proliferation and apoptosis of the HCC cell line Hep3B was investigated. Both drugs significantly inhibited Hep3B cell viability and promoted apoptosis, and these effects were enhanced when these drugs were used in combination. These results suggest that combined genistein and gefitinib treatment exerted increased anti-proliferative and pro-apoptotic effects, compared with genistein or gefitinib alone. In addition, a previous study has also shown that combined genistein and gefitinib treatment enhanced the effect of growth inhibition and apoptosis on non-small cell lung cancer, where the strongest synergistic effect was observed at low concentrations (31).

To explore the role of genistein in combination with gefitinib in cell proliferation and apoptosis further the expression levels of proteins associated with apoptosis, EGFR and PDGF, were determined. The caspase protein family serves important roles in apoptosis. Caspase-3 is the activator of apoptosis where it can enzymatically cleave PARP (32). Downstream, PARP is a multifunctional post-translational modification enzyme that recognizes structurally damaged DNA fragments. PARP cleavage by caspase- 3 increases cell instability and promotes apoptosis $(32,33)$. The results of the present study revealed that genistein in combination with gefitinib displayed the strongest effect on the activation of caspase-3 and PARP compared with the other three groups tested, which caused PARP to lose its enzymatic activity and promote apoptosis. EGFR and PDGF have been demonstrated to promote the division of epithelial cells and proliferation of liver cancer cells (34-36). The present study demonstrated that the expression levels of EGFR and PDGF in the combination group were significantly lower compared with genistein and gefitinib groups alone. Previous studies have found that gefitinib inhibited proliferation by suppressing EGFR (37) whereas genistein has also been demonstrated to inhibit EGFR and PDGF in tumor cells $(38,39)$. These results suggest that genistein promoted the effects of gefitinib by inhibiting the expression of EGFR and PDGF.

The downstream mechanism by which genistein in combination with gefitinib inhibited HCC Hep3B cell growth was subsequently explored by assessing the Akt/Erk/mTOR pathway. Gefitinib and genistein have been previously 
A
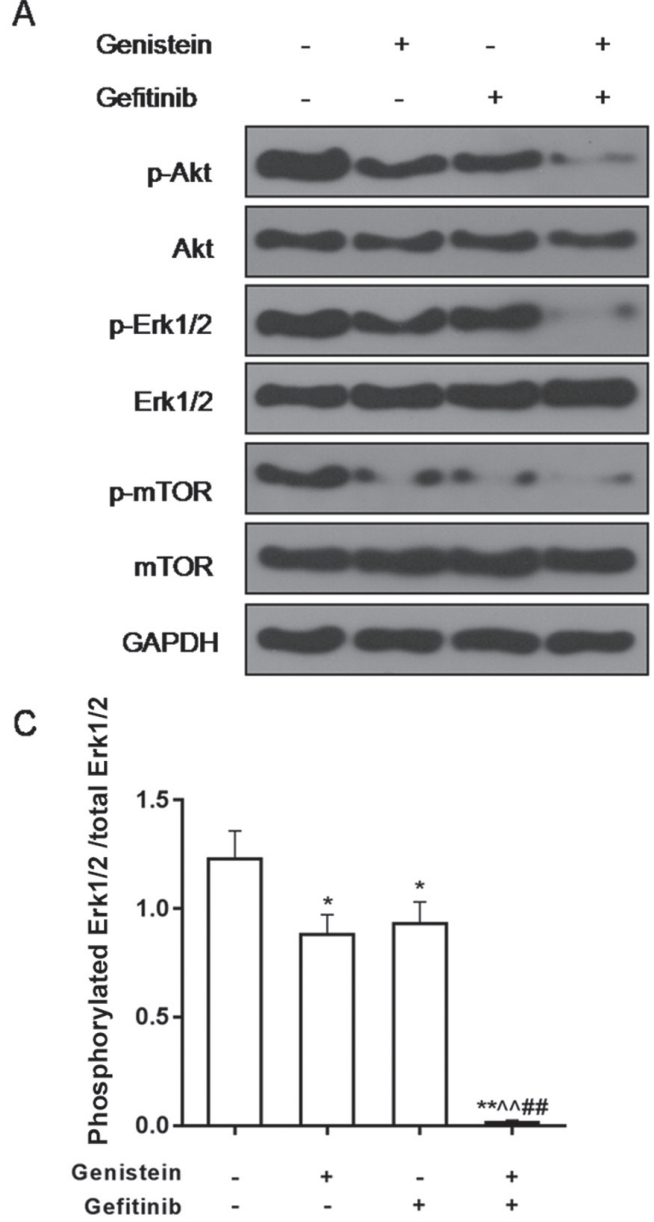

B

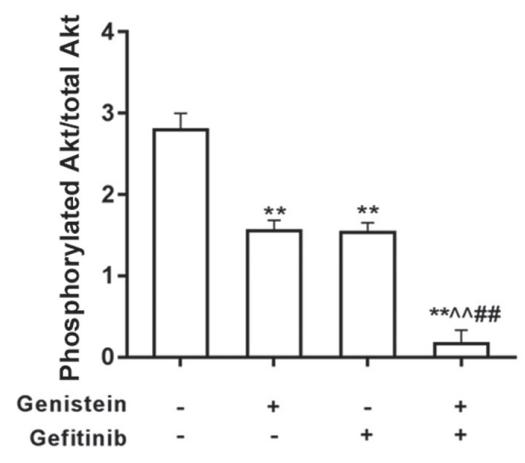

D

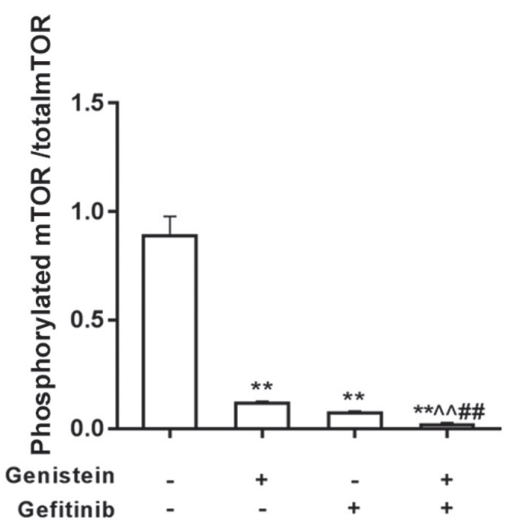

Figure 4. Effects of genistein and gefitinib on the Akt/Erk/mTOR pathway in Hep3B cells using western blot analysis. (A) Representative blots displaying the expression levels of Akt, p-Akt, Erk, p-Erk, mTOR and p-mTOR proteins. Quantified data of (B) Akt and p-Akt, (C) Erk and p-Erk and (D) mTOR and p-mTOR protein expression in genistein alone, gefitinib alone and combination groups. ${ }^{*} \mathrm{P}<0.05$ and ${ }^{* *} \mathrm{P}<0.01$ vs. control; ${ }^{\# \#} \mathrm{P}<0.01$ vs. genistein group; ${ }^{\wedge} \mathrm{P}<0.01$ vs. gefitinib group. p-, phosphorylated.

observed to act on EGFR, where the PI3K/Akt/mTOR and MAPK signaling pathways were the most important signal transduction pathways downstream of EGFR $(40,41)$. Therefore, the effects of genistein and gefitinib on the $\mathrm{Akt} / \mathrm{Erk} / \mathrm{mTOR}$ signaling were investigated in the current study. Total Akt, Erk and mTOR protein levels remained relatively stable in all treatment groups; however, their phosphorylation levels decreased significantly. The levels of $\mathrm{p}$-Akt, $\mathrm{p}$-Erk, and p-mTOR in the combination group were significantly lower compared with genistein or gefitinib alone. Akt, alternatively known as protein kinase $\mathrm{B}$, is an important downstream molecule of PI3K and serves an important role in the regulation of cell growth, proliferation, survival and glucose metabolism. Akt can modulate mTOR either directly or through Erk $(42,43)$. mTOR is a type of serine/threonine kinase and activated mTOR promotes the phosphorylation of substrates S6 kinase (S6K) and 4E binding protein 1 (42). As both substrates are key regulators of protein translation, their phosphorylation leads to the initiation and increase in ribosomal protein synthesis. When mTOR activation is inhibited, cells undergo cell cycle arrest at the G1 phase and apoptosis (44). Previous studies have shown that genistein and gefitinib inhibited cell proliferation by reducing mTOR phosphorylation in cervical cancer cells and breast cancer cells $(45,46)$. The present study suggested that the combination of genistein and gefitinib synergistically exerted anti-proliferative and pro-apoptotic effects by inhibiting the activation of the Akt/Erk/mTOR pathway. Indeed, the Akt-mTOR-p70 S6K pathway has been reported to be overactivated and may serve as a potential target in HCC therapy (47). Therefore, p70S6K activity may also have been inhibited in this study. In addition, a previous study has shown that the Akt/Erk/mTOR pathway was associated with cell autophagy in cancer cells (12). Therefore, it would be beneficial to investigate the effect of genistein and gefitinib on HCC cell autophagy in the future. Genistein has been reported to exhibit multi-targeted biological and molecular effects on cancer cells (15), and the specific inhibition of tyrosine-specific protein kinases is one of the best documented (14). Therefore, it would be of interest to validate the mechanism in which genistein acts to enhance the antitumor effects of gefitinib.

In conclusion, genistein in combination with gefitinib could synergistically inhibit HCC cell proliferation and promote apoptosis, in a more powerful manner compared with either applied alone. Such a phenomenon may be associated with the inhibition of the Akt/Erk/mTOR pathway. The present study provides support for the clinical application of genistein-gefitinib combination treatment on HCC. 


\section{Acknowledgements}

Not applicable.

\section{Funding}

The present study was supported by Zhejiang Science and Technology Department Public Welfare Project (grant no. 2016C37149).

\section{Availability of data and materials}

The datasets used and/or analyzed during the current study are available from the corresponding author on reasonable request.

\section{Authors' contributions}

YT and MW performed western blot analysis and RT-qPCR. $\mathrm{HH}$ and JZ performed flow cytometry assay. YH detected cell cytotoxicity. YC and HP analyzed data and wrote the manuscript. All authors read and approved the final manuscript.

\section{Ethical approval and consent to participate}

Not applicable.

\section{Patient consent for publication}

Not applicable.

\section{Competing interests}

The authors declare that they have no competing interests.

\section{References}

1. Hartke J, Johnson M and Ghabril M: The diagnosis and treatment of hepatocellular carcinoma. Semin Diagn Pathol 34: 153-159, 2017.

2. Costentin C: Hepatocellular carcinoma surveillance. Presse Med 46: 381-385, 2017 (In French).

3. Jiang JF, Lao YC, Yuan BH, Yin J, Liu X, Chen L and Zhong JH: Treatment of hepatocellular carcinoma with portal vein tumor thrombus: Advances and challenges. Oncotarget 8: 33911-33921, 2017.

4. Bruix J, Gores GJ and Mazzaferro V: Hepatocellular carcinoma: Clinical frontiers and perspectives. Gut 63: 844-855, 2014.

5. Hsueh KC, Lee TY, Kor CT, Chen TM, Chang TM, Yang SF and Hsieh CB: The role of liver transplantation or resection for patients with early hepatocellular carcinoma. Tumour Biol 37 4193-4201, 2016

6. Hollebecque A, Malka D, Ferte C, Ducreux M and Boige V: Systemic treatment of advanced hepatocellular carcinoma: From disillusions to new horizons. Eur J Cancer 51: 327-339, 2015.

7. Qi XS, Guo XZ, Han GH, Li HY and Chen J: MET inhibitors for treatment of advanced hepatocellular carcinoma: A review. World J Gastroenterol 21: 5445-5453, 2015.

8. Abdel-Rahman O and Fouad M: Sorafenib-based combination as a first line treatment for advanced hepatocellular carcinoma: A systematic review of the literature. Crit Rev Oncol Hematol 91: $1-8,2014$.

9. Paez JG, Jänne PA, Lee JC, Tracy S, Greulich H, Gabriel S, Herman P, Kaye FJ, Lindeman N, Boggon TJ, et al: EGFR mutations in lung cancer: Correlation with clinical response to gefitinib therapy. Science 304: 1497-1500, 2004.

10. Liu BN, Yan HQ, Wu X, Pan ZH, Zhu Y, Meng ZW, Zhou QH and $\mathrm{Xu} \mathrm{K}$ : Apoptosis induced by benzyl isothiocyanate in gefitinib-resistant lung cancer cells is associated with Akt/MAPK pathways and generation of reactive oxygen species. Cell Biochem Biophys 66: 81-92, 2013.
11. Zhao ZQ, Yu ZY, Li J and Ouyang XN: Gefitinib induces lung cancer cell autophagy and apoptosis via blockade of the PI3K/AKT/mTOR pathway. Oncol Lett 12: 63-68, 2016.

12. $\mathrm{Lu} \mathrm{PH}$, Kuo TC, Chang $\mathrm{KC}$, Chang $\mathrm{CH}$ and $\mathrm{Chu} \mathrm{CY}$ : Gefitinib-induced epidermal growth factor receptor-independent keratinocyte apoptosis is mediated by the JNK activation pathway. Br J Dermatol 164: 38-46, 2011.

13. Schiffer E, Housset C, Cacheux W, Wendum D, DesboisMouthon C, Rey C, Clergue F, Poupon R, Barbu V and Rosmorduc O: Gefitinib, an EGFR inhibitor, prevents hepatocellular carcinoma development in the rat liver with cirrhosis. Hepatology 41: 307-314, 2005.

14. Akiyama T, Ishida J, Nakagawa S, Ogawara H, Watanabe S, Itoh N, Shibuya M and Fukami Y: Genistein, a specific inhibitor of tyrosine-specific protein kinases. J Biol Chem 262: 5592-5595, 1987.

15. Banerjee S, Li Y, Wang Z and Sarkar FH: Multi-targeted therapy of cancer by genistein. Cancer Lett 269: 226-242, 2008.

16. Li S, Li J, Dai W, Zhang Q, Feng J, Wu L, Liu T, Yu Q, Xu S, Wang W, et al: Genistein suppresses aerobic glycolysis and induces hepatocellular carcinoma cell death. Br J Cancer 117: 1518-1528, 2017.

17. Gruca A, Krawczyk Z, Szeja W, Grynkiewicz G and Rusin A: Synthetic genistein glycosides inhibiting EGFR phosphorylation enhance the effect of radiation in HCT 116 colon cancer cells. Molecules 19: 18558-18573, 2014.

18. Livak KJ and Schmittgen TD: Analysis of relative gene expression data using real-time quantitative PCR and the 2(-Delta Delta C(T)) method. Methods 25: 402-408, 2001.

19. Wu JF, Ji J, Dong SY, Li BB, Yu ML, Wu DD, Tao L and Tong XH: Gefitinib enhances oxaliplatin-induced apoptosis mediated by Src and PKC-modulated gap junction function. Oncol Rep 36: 3251-3258, 2016.

20. Maemondo M, Inoue A, Kobayashi K, Sugawara S, Oizumi S, Isobe H, Gemma A, Harada M, Yoshizawa H, Kinoshita I, et al: Gefitinib or chemotherapy for non-small-cell lung cancer with mutated EGFR. N Engl J Med 362: 2380-2388, 2010.

21. Kishida O, Miyazaki Y, Murayama Y, Ogasa M, Miyazaki T, Yamamoto T, Watabe K, Tsutsui S, Kiyohara T, Shimomura I and Shinomura Y: Gefitinib ('Iressa', ZD1839) inhibits SN38-triggered EGF signals and IL-8 production in gastric cancer cells. Cancer Chemother Pharmacol 55: 584-594, 2005.

22. Yang T, Gu J, Liu T, Ma H, Ma X, Tao J, Jin Y and Liang X: Expression of acetaldehyde dehydrogenase in gefitinib-resistant human lung adenocarcinoma HCC-827/GR cells. Zhongguo Fei Ai Za Zhi 21: 431-436, 2018 (In Chinese).

23. Nakashima S, Koike T and Nozawa Y: Genistein, a protein tyrosine kinase inhibitor, inhibits thromboxane A2-mediated human platelet responses. Mol Pharmacol 39: 475-480, 1991.

24. Papazisis KT, Zambouli D, Kimoundri OT, Papadakis ES, Vala V, Geromichalos GD, Voyatzi S, Markala D, Destouni E, Boutis L and Kortsaris AH: Protein tyrosine kinase inhibitor, genistein, enhances apoptosis and cell cycle arrest in K562 cells treated with gamma-irradiation. Cancer Lett 160: 107-113, 2000.

25. van Duursen MB, Nijmeijer SM, de Morree ES, de Jong PC and van den Berg M: Genistein induces breast cancer-associated aromatase and stimulates estrogen-dependent tumor cell growth in in vitro breast cancer model. Toxicology 289: 67-73, 2011.

26. Geller J, Sionit L, Partido C, Li L, Tan X, Youngkin T, Nachtsheim D and Hoffman RM: Genistein inhibits the growth of human-patient BPH and prostate cancer in histoculture. Prostate 34: 75-79, 1998.

27. Tian T, Li J, Li B, Wang Y, Li M, Ma D and Wang X: Genistein exhibits anti-cancer effects via down-regulating FoxM1 in H446 small-cell lung cancer cells. Tumour Biol 35: 4137-4145, 2014.

28. Han C, Michalopoulos GK and Wu T: Prostaglandin E2 receptor EP1 transactivates EGFR/MET receptor tyrosine kinases and enhances invasiveness in human hepatocellular carcinoma cells. J Cell Physiol 207: 261-270, 2006.

29. Wang W, Ma XP, Shi Z, Zhang P, Ding DL, Huang HX, Saiyin HG, Chen TY, Lu PX, Wang NJ, et al: Epidermal growth factor receptor pathway polymorphisms and the prognosis of hepatocellular carcinoma. Am J Cancer Res 5: 396-410, 2014

30. Lin J, Wu L, Bai X, Xie Y, Wang A, Zhang H, Yang X, Wan X, Lu X, Sang X and Zhao H: Combination treatment including targeted therapy for advanced hepatocellular carcinoma. Oncotarget 7: 71036-71051, 2016. 
31. Zhu H, Cheng H, Ren Y, Liu ZG, Zhang YF and De Luo B Synergistic inhibitory effects by the combination of gefitinib and genistein on NSCLC with acquired drug-resistance in vitro and in vivo. Mol Biol Rep 39: 4971-4979, 2012.

32. Boulares AH, Yakovlev AG, Ivanova V, Stoica BA, Wang G, Iyer S and Smulson M: Role of poly(ADP-ribose) polymerase (PARP) cleavage in apoptosis. Caspase 3-resistant PARP mutant increases rates of apoptosis in transfected cells. J Biol Chem 274 22932-22940, 1999.

33. Luo H, Liang H, Chen J, Xu Y, Chen Y, Xu L, Yun L, Liu J, Yang H, Liu L, et al: Hydroquinone induces TK6 cell growth arrest and apoptosis through PARP-1/p53 regulatory pathway. Environ Toxicol 32: 2163-2171, 2017.

34. Xu J, Zhang X, Wang H, Ge S, Gao T, Song L, Wang X, Li H, Qin Y and Zhang Z: HCRP1 downregulation promotes hepatocellular carcinoma cell migration and invasion through the induction of EGFR activation and epithelial-mesenchymal transition. Biomed Pharmacother 88: 421-429, 2017.

35. Lv X, Fang C, Yin R, Qiao B, Shang R, Wang J, Song W, He Y and Chen Y: Agrin para-secreted by PDGF-activated human hepatic stellate cells promotes hepatocarcinogenesis in vitro and in vivo. Oncotarget 8: 105340-105355, 2017.

36. Wang R, Li Y, Hou Y, Yang Q, Chen S, Wang X, Wang Z, Yang Y, Chen C, Wang Z and Wu Q: The PDGF-D/miR-106a/Twist1 pathway orchestrates epithelial-mesenchymal transition in gemcitabine resistance hepatoma cells. Oncotarget 6: 7000-7010, 2015.

37. Ni J, Zhou LL, Ding L, Zhao X, Cao H, Fan F, Li H, Lou R, Du Y, Dong S, et al: PPAR $\gamma$ agonist efatutazone and gefitinib synergistically inhibit the proliferation of EGFR-TKI-resistant lung adenocarcinoma cells via the PPARgamma/PTEN/Akt pathway. Exp Cell Res 361: 246-256, 2017.

38. Nakamura H, Wang Y, Kurita T, Adomat H, Cunha GR and Wang Y: Genistein increases epidermal growth factor receptor signaling and promotes tumor progression in advanced human prostate cancer. PLoS One 6: e20034, 2011.

39. Little PJ, Getachew R, Rezaei HB, Sanchez-Guerrero E, Khachigian LM, Wang H, Liao S, Zheng W, Ballinger ML and Osman N: Genistein inhibits PDGF-stimulated proteoglycan synthesis in vascular smooth muscle without blocking PDGF receptor phosphorylation. Arch Biochem Biophys 525: 25-31, 2012.
40. Ono M and Kuwano M: Molecular mechanisms of epidermal growth factor receptor (EGFR) activation and response to gefitinib and other EGFR-targeting drugs. Clin Cancer Res 12: 7242-7251, 2006.

41. Tanjak P, Thiantanawat A, Watcharasit P and Satayavivad J Genistein reduces the activation of AKT and EGFR, and the production of IL6 in cholangiocarcinoma cells involving estrogen and estrogen receptors. Int J Oncol 53: 177-188, 2018.

42. Bodine SC, Stitt TN, Gonzalez M, Kline WO, Stover GL, Bauerlein R, Zlotchenko E, Scrimgeour A, Lawrence JC, Glass DJ and Yancopoulos GD: Akt/mTOR pathway is a crucial regulator of skeletal muscle hypertrophy and can prevent muscle atrophy in vivo. Nat Cell Biol 3: 1014-1019, 2001.

43. MissiagliaE, Dalai I,Barbi S,BeghelliS,Falconi M,dellaPeruta M, Piemonti L, Capurso G, Di Florio A, delle Fave G, et al: Pancreatic endocrine tumors: Expression profiling evidences a role for AKT-mTOR pathway. J Clin Oncol 28: 245-255, 2010.

44. Zoncu R, Efeyan A and Sabatini DM: mTOR: From growth signal integration to cancer, diabetes and ageing. Nat Rev Mol Cell Biol 12: 21-35, 2011.

45. Sahin K, Tuzcu M, Basak N, Caglayan B, Kilic U, Sahin F and Kucuk O: Sensitization of cervical cancer cells to cisplatin by genistein: The role of NFKB and Akt/mTOR signaling pathways. J Oncol 2012: 461562, 2012.

46. Block M, Gründker C, Fister S, Kubin J, Wilkens L, Mueller MD, Hemmerlein B, Emons G and Günthert AR: Inhibition of the $\mathrm{AKT} / \mathrm{mTOR}$ and erbB pathways by gefitinib, perifosine and analogs of gonadotropin-releasing hormone I and II to overcome tamoxifen resistance in breast cancer cells. Int J Oncol 41: 1845-1854, 2012.

47. Li W, Tan D, Zhang Z, Liang JJ and Brown RE: Activation of Akt-mTOR-p70S6K pathway in angiogenesis in hepatocellular carcinoma. Oncol Rep 20: 713-719, 2008.

This work is licensed under a Creative Commons

Attribution-NonCommercial-NoDerivatives 4.0 International (CC BY-NC-ND 4.0) License. 